\title{
INTERACTIVE TRAINING SIMULATOR AS MEANS OF INCREASING ECONOMIC EFFICIENCY OF ENTERPRISES
}

\author{
Gubin Vladimir Viacheslavovich \\ $\mathrm{PhD}$ in eng. sc., assistant lecturer \\ Department of technological process automation and production \\ Saint-Petersburg Mining University, Russia \\ Darin Aleksey Aleksandrovich \\ $\mathrm{PhD}$ in eng. sc., associate professor \\ Department of technological process automation and production \\ Saint-Petersburg Mining University, Russia
}

\begin{abstract}
.
Computer training of technological process operators is recognized worldwide as an effective means of reducing accidents and increasing production efficiency by improving operator's skills.

The use of computer simulators for training operators of potentially dangerous industries is fixed in regulatory documents of many countries, including Russia. Most enterprises in the oil and gas industry have already equipped their training centers with computer simulators; however, the metallurgical sector and other representatives of the chemical engineering industries do not use and often do not consider a computer simulator as a tool for improving efficiency and production safety.

World statistics shows that among the causes of industrial accidents, operator mistakes are firmly in second place. They account for an average of $40 \%$ of all emergency incidents.

Computer training is the most powerful and effective means of dealing with the operators mistakes. With the help of a specialized simulator, with a high degree of accuracy, imitating the work of a dangerous technological installation, relating to the oil refining or metallurgical industry, it is possible not only to familiarize operators with potential emergencies and develop a strategy for preventing accidents, mitigating or eliminating its consequences, but also working out actions operators to automatism. A good full-scale simulator allows to work out detailed measures to prevent accidents, as well as plans for the localization and liquidation of emergencies.

The article presents an overview of the current state of the industry of technological simulators, examines existing technical solutions, global manufacturers and simulators using aspects.
\end{abstract}


Keywords: industrial simulator, operator training simulator (OTS), production efficiency, production safety

Cite this Article: Gubin Vladimir Viacheslavovich and Darin Aleksey Aleksandrovich, Interactive Training Simulator as Means of Increasing Economic Efficiency of Enterprises, International Journal of Management, 10 (2), 2019, pp. 122-126.

http://iaeme.com/Home/issue/IJM?Volume=10\&Issue $=2$

\section{INTRODUCTION}

Nowadays, performance management is one of the main trends in the development of enterprises and improvement of production and economic indicators. The idea of performance management is mainly related to personnel management and consists in the transition from the "command-and-control" style of production management to more flexible and modern models, when the employee is guided by the strategic objectives of the enterprise. An important issue is also reducing of the accidents possibility caused by personnel through the modernization of measures to ensure industrial safety [1].

Qualitative improvement of the information support system for subsoil use, monitoring and control through the development of information technologies, including implementation of automated control and regulation systems, is one of the strategic objectives of Russian enterprises $[2,3]$.

A feature of all automated systems introduced at the plants of ferrous and non-ferrous metallurgy can be considered a systematic approach to all the processes occurring within the enterprise. These include heat engineering, environmental, metallurgical and management processes $[4,5,6]$. It is important to build not only the management of thermal processes, but also to establish their uninterrupted flow. This significantly improves the quality of the product, saves costs and increases productivity. In the metallurgical industry, the implementation of complex automation is justified, which makes it possible to subordinate all areas of enterprise activity to a single management center. This applies to the department of supply of raw materials, loading system of furnace, exhaust lines, accounting, technical control, etc.

Professional development and retraining is inherently connected with the development of specialized educational programs, both within the framework of training complexes and programs of professional education implemented on the basis of higher educational institutions [7].

As the level of industrial automation increases, so does the role of operators. If earlier their activities consisted mainly in manual manipulation, now that many functions are performed automatically by the distributed control system (DCS), operators are required to have a deeper understanding of the technological process (TP) and the ability to use all the controls at their disposal to bring the installation to the most cost-effective mode: with the help of APC-system (Advanced Process Control) or without it $[8,9]$.

\section{DESIGN AND OPERATION FEATURES}

There are several fundamental elements of the simulator that distinguish it from other learning tools:

1. Model of a real object, created due to the fact that a real object is impossible, dangerous or expensive to use for training.

2. Information model - the environment of student interaction with the object model. With its help, the trainee acts on the training model and receives information about its condition.

3. Model of learning. Those rules, methods and a certain composition of training exercises and other attributes of training. 
One of the criteria for the quality of the simulator is the ability to transfer training skills to real activity in a production environment, which depends on the quality of all components of the simulator, especially on simulation models of the technological process $[10,11]$.

The principle of achieving such a transfer is to ensure the maximum similarity of the student's activities in training and in actual practice.

A computer simulator is a software and hardware complex that includes at least:

- a simulating station (it solves a system of algebraic and differential equations describing the TP model);

- Student workstation (they implement an information model);

- Instructor workstation (to organize and track the course of training).

In this case, the simulation station, as a rule, is combined on the same PC with the instructor's, since the characteristics of modern PCs allow multitasking simultaneously and calculate several training models and implement instructor functions.

Since the training platform is not only a training tool, but also a tool for the development, configuration and modification of the simulator, an engineering station can be allocated in large projects. (Usually it is also combined with the instructor station, and system modification options are available at higher levels of the user). Finally, with a large number of control points in the simulator, a separate remote control station can be allocated, although these functions can easily be performed from the instructor station.

The main architectural solution is the use of a local area network, in which the instructor station is connected to several operator stations. In addition to economic considerations (efficient use of instructor training time), this approach is explained by similarity requirements. In the training, as in the real object, the operator must be fully responsible for their TP part:

- From the workplace, there shall be no intervention in the TP or other operators, or instructors. Moreover, the intervention of an instructor who simulates changes in the external environment or equipment failures should be unexpected for the trainee, and therefore be carried out remotely.

- when working out the actions of the change of operators, which is often an important task of the training, each student should have from his workplace not only access to the management of the TP assigned to him, but also all information about changes in the behavior of the process due to the interventions of other operators.

The simulator model is increasingly seen as part of the overall production model within the concept of "real-time optimization". With this approach, the "full" simulation model of the technological object is used for technological engineering (checking bottlenecks, checking new technological modes), and for the engineering of control systems (setting up and testing the control system; setting up advanced control systems; alarm management), and for knowledge engineering (operator training), and for other purposes.

In this regard, it is possible that the simulators may become in the future as a part of the systems for a wider purpose.

Achievements of engineering psychology in the field of construction of effective schemes of computer training of operator skills are transformed into fundamentally new capabilities of instructor stations (automated systems for the formation of individual and complex skills; automated testing systems, etc.).

\section{MANUFACTURERS}

The main manufacturers of simulators often are manufacturers of control systems (such as ABB, Invensys, Honeywell), having simulator production departments. 
Since one of the main motives of the order for the simulator is the modernization or change of the control system, it is the manufacturer of the control system that has more chances to ensure the desired quality of the simulator, especially since many of these companies increasingly have rights to all or most of the products included in the simulator. The most striking example is Schneider Electric Corporation, which in January 2014 completed the acquisition of Invensys, which owns a well-known supplier of DCS (Foxboro), and a model developer (SimSci), as well as a developer of SCADA-interfaces (InTouch).

Also, a company specializing in fundamental modeling of technological processes (TP), such as Aspen and Hyprotech (with its own training solutions), can become a manufacturer of simulators. The strength of such a developer - rich libraries of training models.

Another example of simulator manufacturers is technology companies (UOP, KBC) or their associated training companies (RSI as part of AXENS). In the case of a simulator for a newly constructed facility, these manufacturers have exclusive technological information, sometimes inaccessible to competitors.

\section{ECONOMIC ASPECTS}

Technology simulator equipped with the tools of economic analysis - an excellent tool of training of the operators of the productive economy.

There is another aspect of the use of simulators in the enterprise, which is most directly related to economists - the cost.

As for the cost of training complexes, foreign manufacturers have them within 200-1000 thousand dollars for specialized one process unit simulator. The cost of standard TP models is usually several times less than specialized ones. Russian manufacturers systems, while remaining an expensive product, however, on average several times cheaper [9, 12].

The recoupment of simulators can be ensured by a general decrease in the accident rate and an increase in the quality of TP control. There are estimates based on global emergency incident statistics. For example, it is estimated that if the acquisition of a computer simulator with a set of models of the main installations of an oil refinery avoids at least one emergency incident caused by the operator out of every three, then the payback period of the entire training complex will be approximately 1 year.

Companies like DuPont or Exxon-Mobil have been using computer training for over 30 years. As an additional economic benefit from the use of simulators DuPont notes energy savings (up to $0.5 \%$ ). And the US Petroleum Institute (API), based on a survey of 200 managers at 11 enterprises of 7 petrochemical companies, estimated the average profit from the training of one operator on computer simulators at 21 thousand dollars per year.

\section{CONCLUSION}

Analysis of trends in the development of the interactive simulators market indicates the interest of the world industry in such means of training of operational personnel in the oil and gas, metallurgical and other industries. The development of TP imitation models will improve the methods of training operators and, as a consequence, reduce the impact of the human factor on the safety of industrial facilities, and increase the economic efficiency of the enterprises.

\section{REFERENCES}

[1] Popov A. N., Ivashova N. S., Deulin A. A., Kalinogorsky D. I., Kunnikov E. U. Risk-based approach in industrial safety / Industrial and ecological safety, labor safety, 2015. No. 2 (99). - pp. 20-22. 
Interactive Training Simulator as Means of Increasing Economic Efficiency of Enterprises, International Journal of Management

[2] Sizyakov V.M., Bazhin V.Yu., Selishcheva T. A., Vlasov A. A. The Role of the state in the sphere of innovative activity of nonferrous metallurgy enterprises of Russia / Metallurgist, 2014. No. 1. - pp. 1-7.

[3] Development strategy of the mineral resource base of the Russian Federation to 2035: the RF Government decree of 22 December 2018. No. 2914. - 31 p.

[4] Beloglazov I. I., Petrov P. A., Martynov S. A. Application of Production Processes Control Algorithm Using Adaptive Control Systemg / International Russian Automation Conference, RusAutoCon, 2018. No. 1. -pp. 1 - 4.

[5] Petuhov A.A., Darin A.A., Telyakov A.A. Processing of ferromanganese nodules of the Pacific Ocean / Metallurgist, 2017. Vol. 61, No. 5-6. pp 439-443

[6] Boduen, A.Y., Fokina, S.B., Polezhaev, S.Y. The hydrometallurgical pretreatment of a refractory gold sulfide concentrate / Innovation-Based Development of the Mineral Resources Sector: Challenges and Prospects - 11th conference of the Russian-German Raw Materials, 2018. - pp. 331-340.

[7] Katuntsov E.V., Kultan J, Makhovikov A.B. Application of Electronic Learning Tools for Training of Specialists in the Field of Information Technologies for Enterprises of Mineral Resources Sector / Journal of Mining Institute, 2017. Vol. 226. -pp. 503-508.

[8] Wisnu Mawardi, Achma Hendra Setiawan, Dul Mu'id, Banatul Hayati and Darwanto, Analysis of Savings and Loan and Shariah Financing Cooperative (Kspps) Role in Developing Micro, Small, and Medium Enterprises (Msmes) Using Structural Equation Modelling-Partial Least Square (Sem-Pls), International Journal of Mechanical Engineering and Technology, 9(11), 2018, pp. 629-642.

[9] Chistov V. P., Zakharova G. B., Kononenko I. A., Titov V. G. Computer simulator for operators of technological processes of blast furnace production / Software products and systems, 2002. No. 3. - pp. 42 - 45.

[10] Dozortsev V. M., Kneller D. V. Technological computer simulators: everything you always wanted to know... / Industrial ACS and controllers, 2004. No. 12. - pp. 1-13.

[11] Taneyev V. V. Application of mathematical models for forecasting of emergency situations in automated process control systems / Mathematical models in automated process control systems: collection of scientific works. - M., 1984. - pp. 33-35.

[12] K. S. Suresh, K.S.Ravichandran, S.Ananthakrishnan, and S. Venugopal, Adaptive strategy to improve the efficiency of robot path planning using population based Algorithm, International Journal of Mechanical Engineering and Technology 8(8), 2017, pp. 1441-1448.

[13] Koteleva H. I., Shablovsky I. E., Koshkin A.V. Computer simulators for training operators of technological processes in the oil and gas industry: analysis of existing solutions and ways to improve them / Journal of Mining Institute, 2011. Vol. 192. - pp. 212-215.

[14] Eben Priya A.R.P, Dr.K.Karthikeyan, A Literature Survey on "Impact of Economic Growth: A Comparison between India and China", International Journal of Civil Engineering and Technology, 9(7), 2018, pp. 747-754.

[15] Dozortsev V. M., Shestakov N. M. Computer simulators for production of chemical and technological type: efficiency, payback / Safety problems in emergency situations, 1997. No. 7. - pp. 247-255.

[16] Omer Gul, An Assessment Of Technical And Economical Problems Based On Reactive Power In Restructured Turkish Power Systems, International Journal of Electrical Engineering and Technology (IJEET), Volume 4, Issue 5, September - October (2013), pp. 206-220 